\title{
Chloroaluminum Phthalocyanine
}

National Cancer Institute

\section{Source}

National Cancer Institute. Chloroaluminum Phthalocyanine. NCI Thesaurus. Code C1048.

A rhodamine-based dye used as a photosensitizing agent in cytotoxic photodynamic therapy. $(\mathrm{NCl})$ 